\title{
CASE STUDY ON VULNERABILITY INCREASE FOR A REINFORCED CONCRETE FRAME STRUCTURE
}

OLTEANU IOANA - Lecturer, PhD, Gheorghe Asachi Technical University of Iasi, Faculty of Civil Engineering and Building Services, email: olteanuioa@yahoo.com

CANARACHE RADU MARIAN - PhD., eng., INICAD DESIGN S.R.L., Bucuresti, radu_canarache@yahoo.com BUDESCU MIHAI - Professor, PhD, “Gh. Asachi” Technical University of Iasi, Faculty of Civil Engineering and Building Services, budescu@ce.tuiasi.ro

\begin{abstract}
Seismic vulnerability for a structure represents the susceptibility to be affected by an event with a given intensity. The vulnerability of a structure can be influenced by the design methods or by different problems that may appear during the execution process.

This paper shows a case study for the vulnerability increase of a reinforced concrete frame structure in 2 different situations:

a) modification produced due to code changes, meaning P100-2006 respectively P100-2013;

b) modifications produced the structure taking into account the errors which have occurred during the execution process;

For both cases, capacity curves were plotted considering the nonlinear analysis, also called pushover. The numerical simulation was performed in SAP2000 software. These curves were compared with the response spectrum corresponding to the site conditions in order to obtain the performance point. For accurate results, fragility curves were plotted for both considered situations, according to previous research of the authors.

The paper emphasizes the importance of each stage during the execution of a structure. More over the differences in the vulnerability index show the importance on the overall behavior of the structure. Solution to increase strength and safety for the structure are also given at the end of the paper.
\end{abstract}

Keywords: push-over analysis, deterministic analysis; vulnerability assessment, fragility curves

\section{Introduction}

A good overall behavior for a structure is determined by a correct design process and rigorous execution stages. There are several factors that can influence the bearing capacity of a structure and sometimes an evaluation of the building vulnerability is required. Usually, this analysis is realized if, for example, a destination change is desired or if some problems are encountered in one of the major stages - design codes are change, if design process is considered or if some inconsistencies are encountered between design and erection process, Fig. 1.

In the situation of structures that cannot fulfill all the general rules of construction details, due to special architectural requirements or due to unexpected execution problems, it is important to be able to evaluate how the seismic vulnerability increases. The paper shows an example where the seismic vulnerability was evaluated for one structure in 2 situations, emphasizing the influence of code modification and erection problems on the overall behavior of the structure.

The analyzed example represents a typical reinforced concrete frame structure with 4 floors designed according to P100-2006 regulations. During execution some problems were encountered and major errors were found in almost all the columns from the ground floor level under the first floor slab, leading to plastic hinges development. By the time the problem was identified the execution has reached the 2 nd floor. The work was stopped and the reevaluation of the structure was done according P100-2013. Additional walls were introduced in order to take over the additional stresses due to inappropriate execution [15]. 


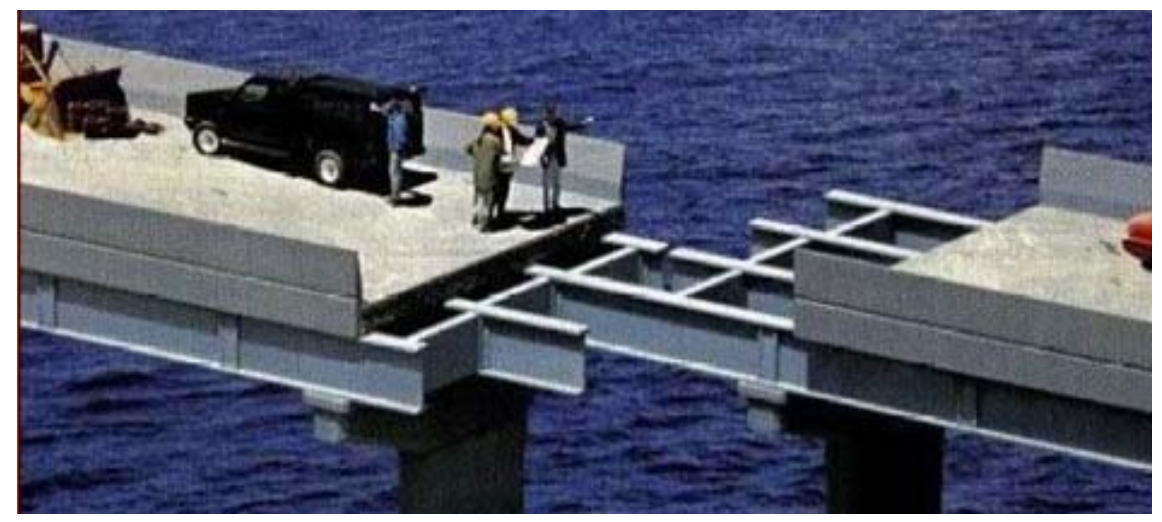

Fig.1 - Example of bad engineering [14]

\section{Vulnerability assessment methodology}

The damages produced by natural disasters in the last 30 years reveal the necessity to reevaluate the built environment. The current trend is to assess the vulnerability and risk of the building stock, not only for a single action, but for a complex loading represented by more natural hazards in order to diminish human and financial losses. The physical seismic vulnerability, which is of interest for this paper purpose, can be evaluated: by qualitative descriptors or variables [6]; by means of physical vulnerability indices [2] and by means of capacity curves.

The capacity curve is widely used in recent research projects concerned with risk assessment, like HAZUS, Risk-UE and CAPRA. The theoretical model is called Capacity Spectrum Method and operates with simplified mechanical models [5], [4], (HAZUS 99-SR2), (RISK-UE), (ERN-AL. CAPRA).

The paper evaluates the seismic vulnerability using the deterministic methodology proposed in Risk-UE project. This method defines building vulnerability from the capacity spectrum and evaluates the expected seismic performance of the structure by comparing the capacity spectrum with the demand spectrum of the seismic hazard [3]. Four damage states are considered in this paper for a building, defined according to Risk-UE handbook specifications, obtaining the damage expressed as probability matrices [7]. Even though the used approaches have been improved significantly, the uncertainties in the structural characteristics and in the damage state thresholds have a great influence on the results.

In order to evaluate the building behavior, capacity curves can be obtained through nonlinear analysis. The pushover analysis is a nonlinear static incremental procedure able to describe, in a simplified way, the structural behavior when subjected to earthquake loading [9], (FEMA-273, 1997). It allows the identification of weak structural members and the failure mechanisms. The capacity curve is in fact the graphical representation of the relation between the base shear and the displacement at the roof of the structure (ATC-40, 1996), [11], [12].

The capacity spectrum method requires the following steps: (1) perform the pushover analysis of the building; (2) plot the capacity curve of the building; (3) represent it in a ADRS format, that is, as a capacity spectrum; (4) calculate and plot the bilinear representation of the capacity spectrum; (5) plot the demand spectrum of the considered earthquake; and finally (6) intersect capacity and demand spectra to obtain the performance point, and thus the expected spectral displacement. Even though there are a variety of methods to evaluate the behavior of the structure, it is considered that the pushover analysis is an accurate approximation in comparison with the nonlinear dynamic analysis. The performance point is calculated using the equal displacement approximation described in ATC-40 [8], [4].

In order to evaluate the seismic risk of a building, damage fragility curves are used. Fragility curves define the probability that the expected global damage $d$ of a structure exceeds a given 
damage state $d s i$, as a function of a parameter quantifying the severity of the seismic action. Thus, for each damage state, the corresponding fragility curve is completely defined by plotting $P[d \geq d s i]$ in the ordinate and the spectral displacement $S d$ in the abscissa. For a given damage state $d s i$, a fragility curve is well described by the following lognormal probability density function [1]:

$$
P[d s i \mid S d]=\Phi\left[\frac{1}{\beta_{d s i}} \ln \left(\frac{S d}{\overline{S d}_{d s i}}\right)\right]
$$

where $S d$ is the spectral displacement (seismic hazard parameter), is the median value of spectral displacement at which the building reaches a certain threshold of the damage state dsi, $\beta_{d s i}$ is the standard deviation of the natural logarithm of the spectral displacement of the damage state ds and $\Phi$ is the standard normal cumulative distribution function. The considered approach proposes four damage states: slight - the damage is considered negligible, moderate - slight structural damage and moderate non-structural damage, severe - moderate structural damage and heavy non-structural damage and collapse when structure is in imminent danger of collapse. Table 1 shows a summary of the used parameters for the damage state thresholds, as functions of the yielding displacement, $d y$, and the ultimate displacement, $d u$, of the structure [7].

Table 1

\section{Damage state thresholds}

\begin{tabular}{|c|c|c|}
\hline $\begin{array}{c}\text { Damage } \\
\text { state }\end{array}$ & $\overline{S d_{d s i}}$ values & $\begin{array}{l}\text { Graphical representation of the damage } \\
\text { thresholds in the bilinear capacity spectrum }\end{array}$ \\
\hline Slight & $0.7 \mathrm{dy}$ & $\uparrow$ \\
\hline Moderate & dy & \\
\hline Severe & $\mathrm{dy}+0.25$ (du-dy) & \\
\hline Collapse & $\mathrm{du}$ & $\begin{array}{l}\frac{1}{\mathrm{Sd}_{1}} \frac{{ }_{\mathrm{Sd}}}{2} \\
\text { Spectral displacem ent, } \mathrm{Sd}\end{array}$ \\
\hline
\end{tabular}

A further step is given by obtaining the vulnerability curve which describes the seismic structural damage. These curves are useful in risk analyses of urban areas, in which case, a library of curves covering all the existing building typologies can be realised. They quantify the damage as a function of a parameter characterizing the seismic action, for example the spectral displacement, Sd. From a theoretical point of view, they represent the normalized mathematical expectation of the damage states in each spectral displacement [10]:

$$
D I=\frac{1}{n} \sum_{i=1}^{n} x_{i} \cdot p_{i}
$$

where $D I$ is the mean damage index, $x_{i}$ is the damage state number which varies from 1 to 4 , and $p_{i}$ is the probability of corresponding damage state. The probability of damage is computed from the fragility curves.

\section{Case study}

\subsection{Stucture description}

The analyzed structure is a reinforced concrete frame structure design initially as a structure with 2 underground levels (upper one is more than $50 \%$ above the natural ground level) + ground level +4 floors. The height of the ground floor is $4.90 \mathrm{~m}$ and the rest of the floors are of $3.70 \mathrm{~m}$. The plan dimensions of the construction are $42.30 \mathrm{~m}$ by $18.30 \mathrm{~m}$. 
The first problem encountered by the designer were that after construction work has started, an additional level was requested by the owner, Fig 2. Another problem was found during execution. As shown in Fig. 3 major errors were found in almost all the columns under the first floor slab, therefore plastic hinges have already appeared. In that moment the execution has reached the $2^{\text {nd }}$ floor.
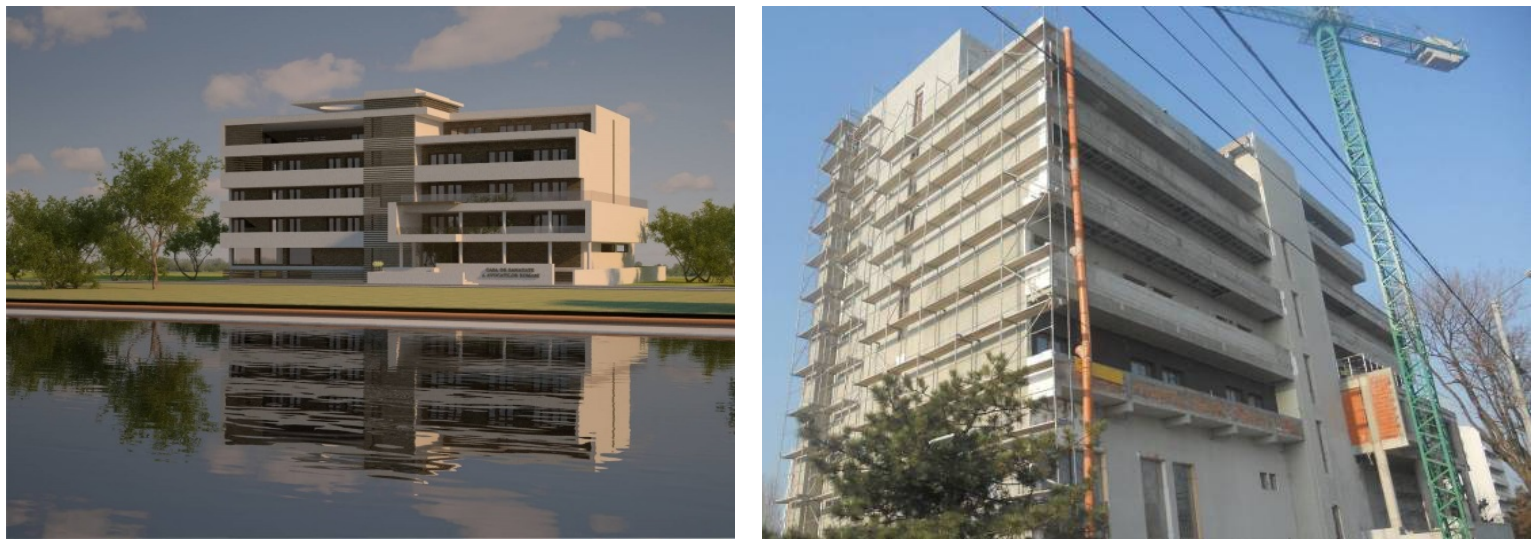

Fig.2 - Initial and final layout of the analyzed building
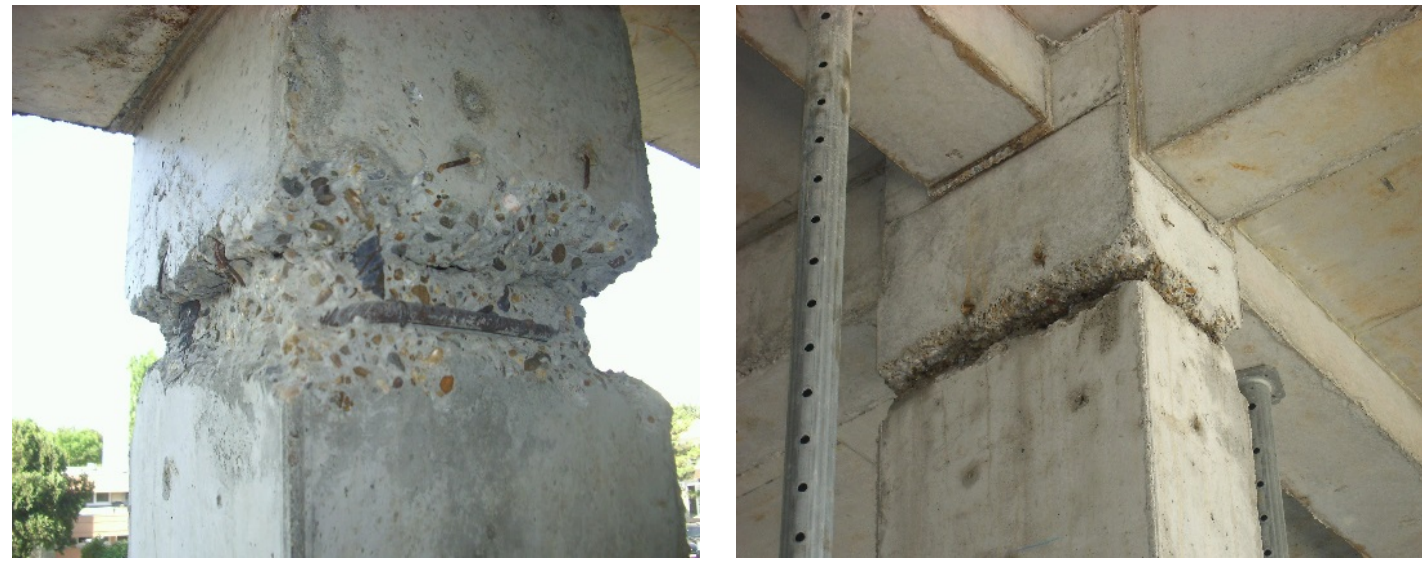

Fig.3 - Ground floor columns

When the reevaluation started, the designer encountered another challenge. If initially the structure was considered in the $3^{\text {rd }}$ class of importance according to national Code P $100 / 2006$, in the same period, proposal for new code appeared. In the new edition of the code it is settled that any building which may cover at least 100 persons should considered in the $2^{\text {nd }}$ class of importance, so a $20 \%$ increase of the seismic force had to be considered for the damaged structure. Also, the peak ground acceleration for the region has increased from $0.16 \mathrm{~g}$ to $0.20 \mathrm{~g}$, so another $25 \%$ should be added for the seismic force.

In this situation the structural system had to be reconsidered, and the designers proposed a mixed structure solution made of reinforced concrete walls and frames. Two major challenges were encountered at this stage: how to position the concrete walls without affecting the layout of the ground floor lobby, and, -more important- the holes for all types of installations and how to connect the new walls in the ground and first floor with the already casted concrete columns (which have only $35 \mathrm{~cm}$ width). The considered solution for the connection was represented by the use of chemical anchors.

\subsection{Results of the static linear and nonlinear analysis}

For the pushover analyzis we have chosen one transversal and one longitudinal frame, with the same layout and load. The capacity curves obtained through SAP2000 computer software for the initial and damage situation were compared, Fig 4 . On the capacity curve the plastic hinges are 
indicated in the order they appear. The blue dot is for the life safety level, the green one for the collapse prevention level and the red one for the totally damaged level. In the moment when the plastic hinges start to appear, the structure has the capacity to redistribute the efforts towards other elements, until the moment when the structure becomes a mechanism and the bearing capacity is exceeded. For the damaged structure, the plastic hinges start to appear for lower displacements and lower shear force values. The structure goes to plastic behavior at a shear force with $30 \%$ less in the damaged cased compared with the initial design structure. The maximum displacement at the top of the considered models is of $21 \mathrm{~cm}$ for the damage case, in comparison with $23 \mathrm{~cm}$ for the initial structure.

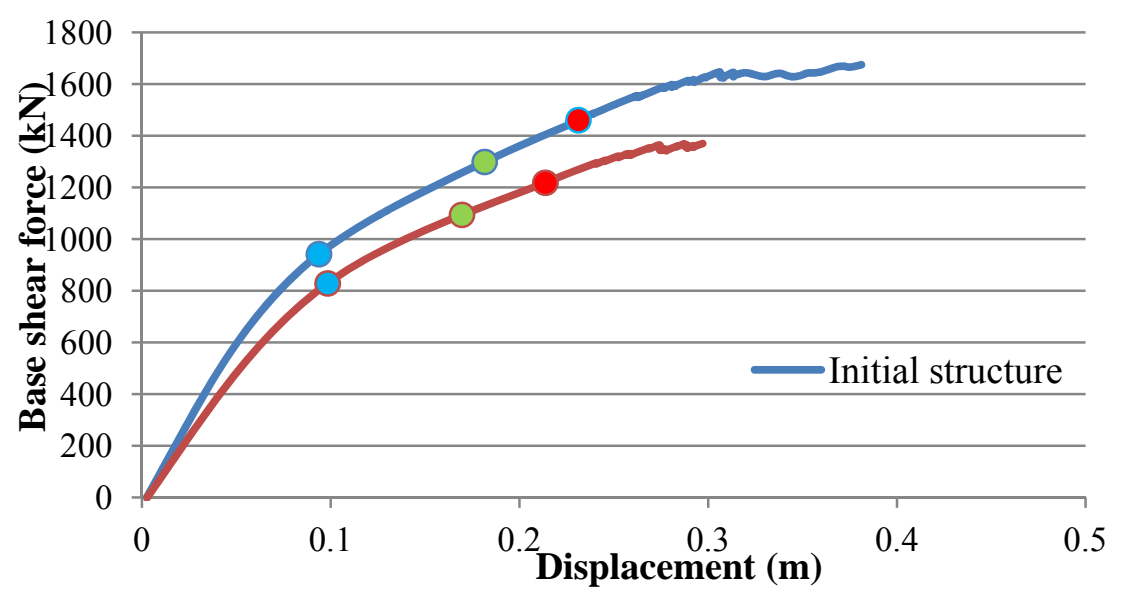

Fig. 4 - Capacity curves for models 1 and 2

\subsection{Vulnerability assessment}

Based on the capacity curves obtained through the nonlinear analysis performed in SAP2000 and on the methodology presented in chapter 2, the damage matrix for each damage state was computed for four considered cases. The pushover results were considered on $\mathrm{x}$ and $\mathrm{y}$ axis respectively, in two situation - initial and damaged situation.

In table 2 the damage probability for each considered state is presented, in case of the four situations. The last column, Dsm, represents an average damage index. These probabilities are computed for the spectral displacement corresponding to the performance point. The performance point was established by comparing the capacity spectrum with the demand spectrum obtained for Vrancea earthquake from 1977.

Table 2

Damage state probabilities

\begin{tabular}{|l|c|c|c|c|c|c|}
\hline \multirow{2}{*}{ Structure name } & \multicolumn{7}{|c|}{ Damage state probabilities } \\
\cline { 2 - 8 } & None & Slight & Moderate & Severe & Collapse & Dsm \\
\hline initial structure_ox & 0,1366 & 0,4334 & 0,4254 & 0,0045 & 0,0000 & 0,2596 \\
\hline damaged structure_ox & 0,0271 & 0,3360 & 0,5891 & 0,0478 & 0,0000 & 0,3315 \\
\hline initial structure_oy & 0,6109 & 0,2735 & 0,1117 & 0,0038 & 0,0000 & 0,1017 \\
\hline damaged structure_oy & 0,5640 & 0,3087 & 0,1163 & 0,0109 & 0,0000 & 0,1148 \\
\hline
\end{tabular}

In it noticed an increase of the damage index on both direction for the damaged structure - the structure with hinges at the ground floor level.

Detailed representation on $\mathrm{x}$ and on $\mathrm{y}$ respectively are presented in Figures 5 and 6 . In ox direction is noticed the major differences appear in the moderate and severe damage state. Meanwhile in oy direction the differences appear in the slight and severe damage state. 


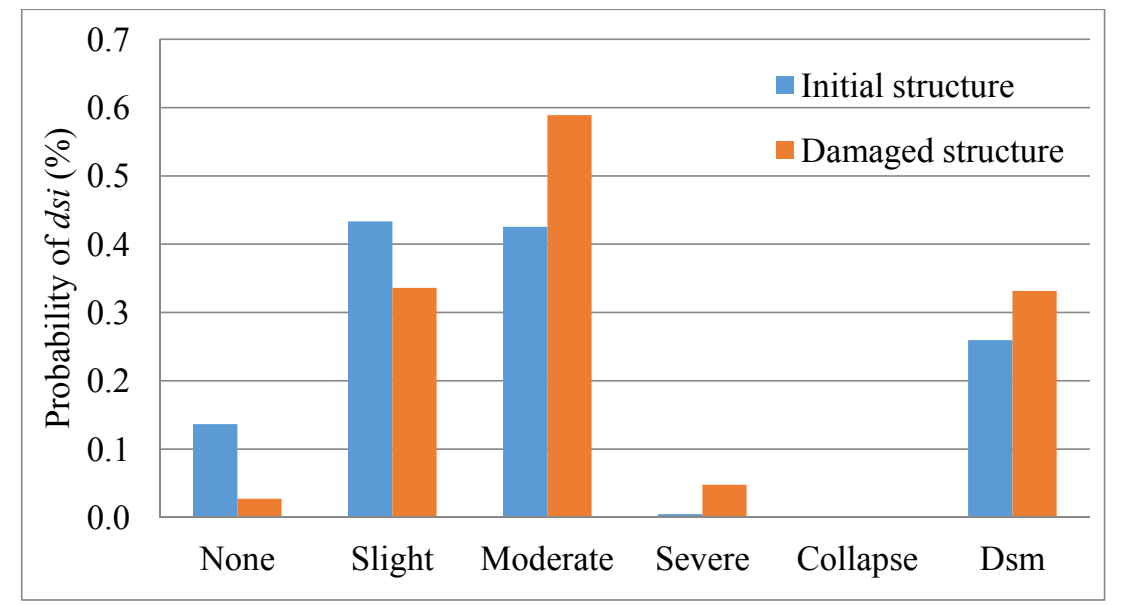

Fig.5 - Damage stages considering push_ox

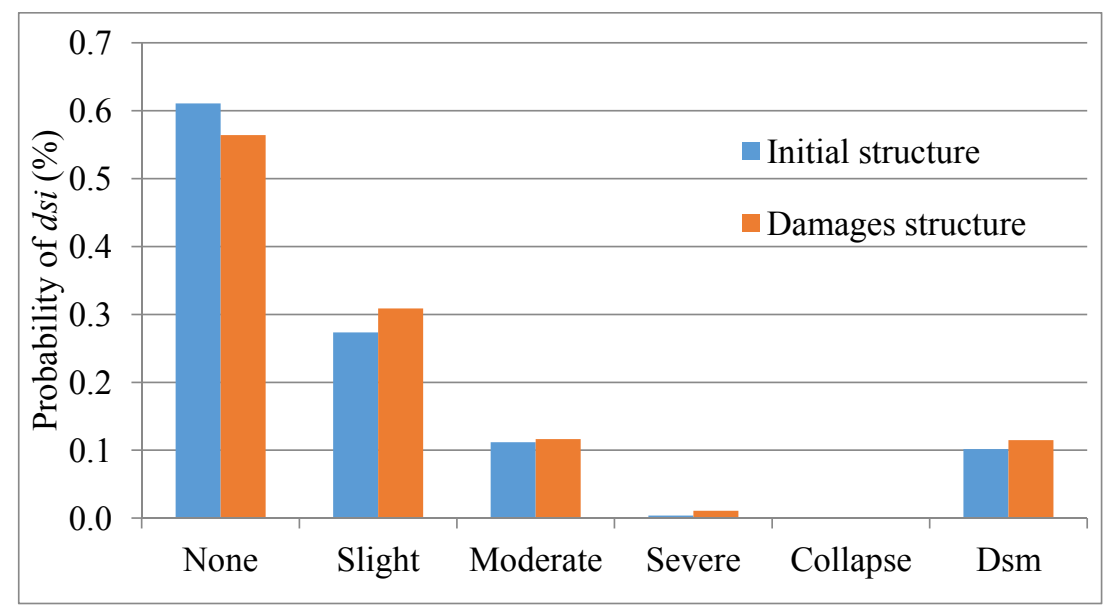

Fig.6 - Damage stages considering push_oy

Fig. 7 presents a detailed representation for the fragility curves for the pushover of the initial structure, when pushover on ox direction is computed. These curves are very important for the vulnerability and risk assessment process, but unfortunately are very difficult to analyze. They give the probability of damage for each damage state at each spectral displacement value. In order to ease the understanding process and to facilitate the solution process, vulnerability curves can be plotted.

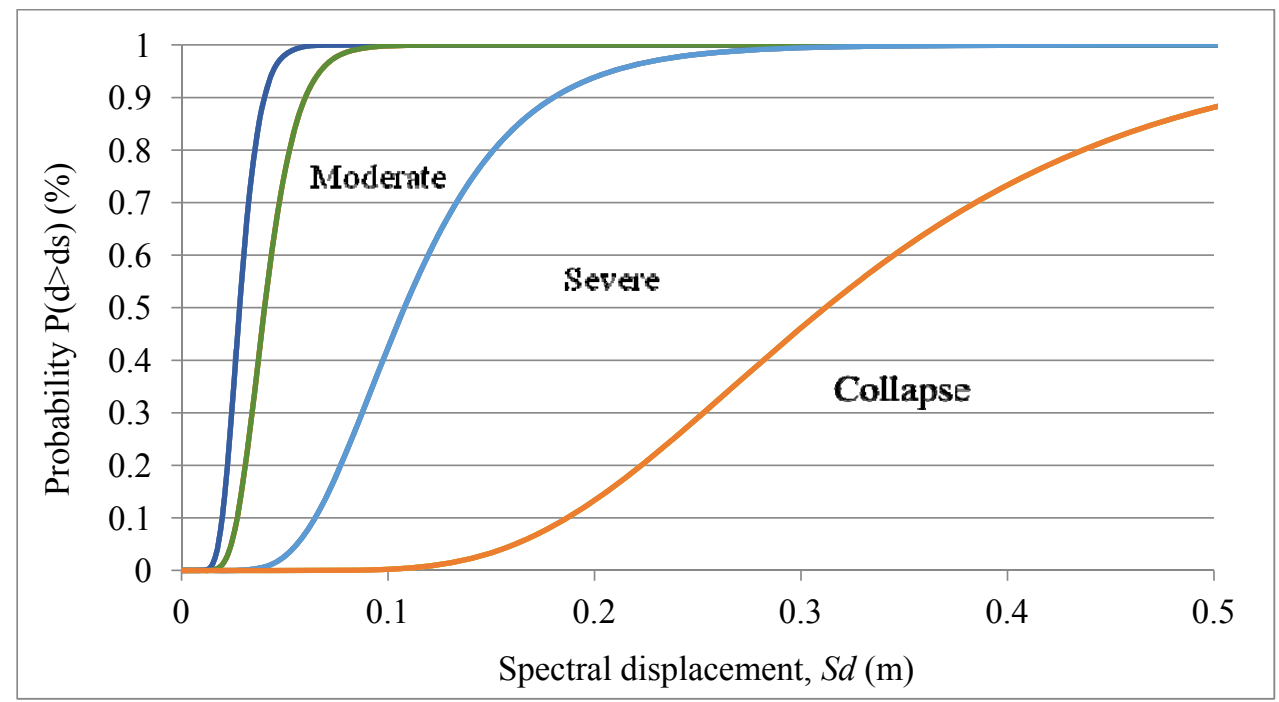

Fig .7 - Fragility curves representation 
Fig. 8 and 9 are vulnerability curves on ox and on oy respectively. The results are similar as for the damaged index computed for the performance point, meaning the hinges in the bottom column lead to a significant increase of the vulnerability of the structure. In order to reduce the effect introduced in the initial design, by the errors that appeared in the execution process, the reevaluation of the structure is required, along with improving solutions.

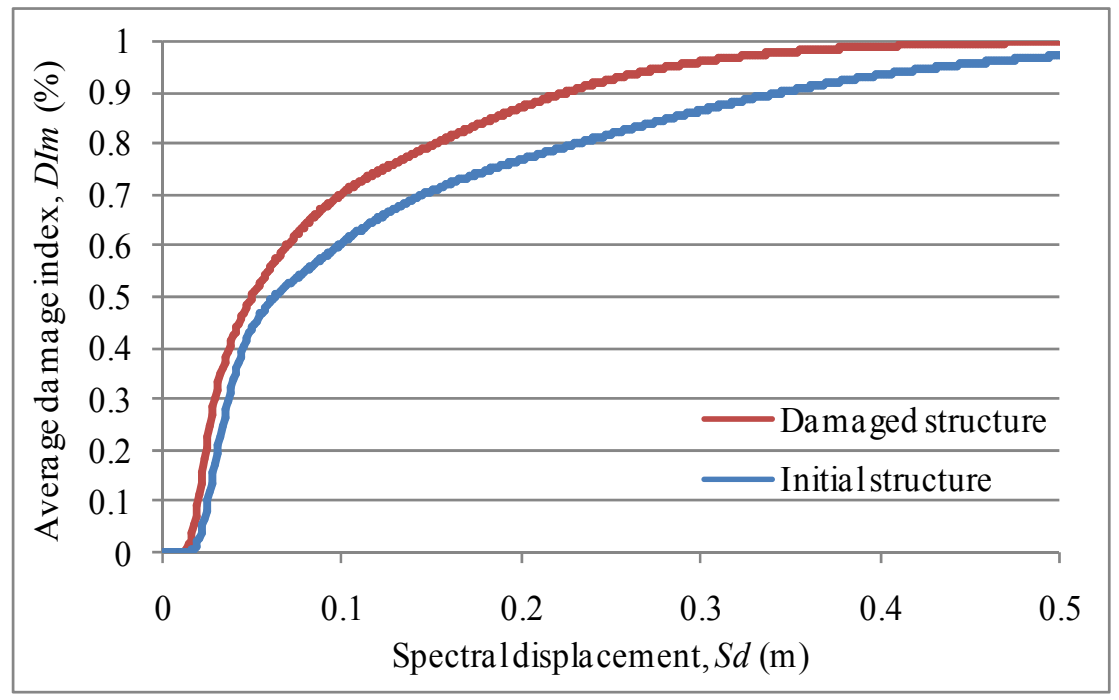

Fig. 8 - Vulnerability curves for ox direction

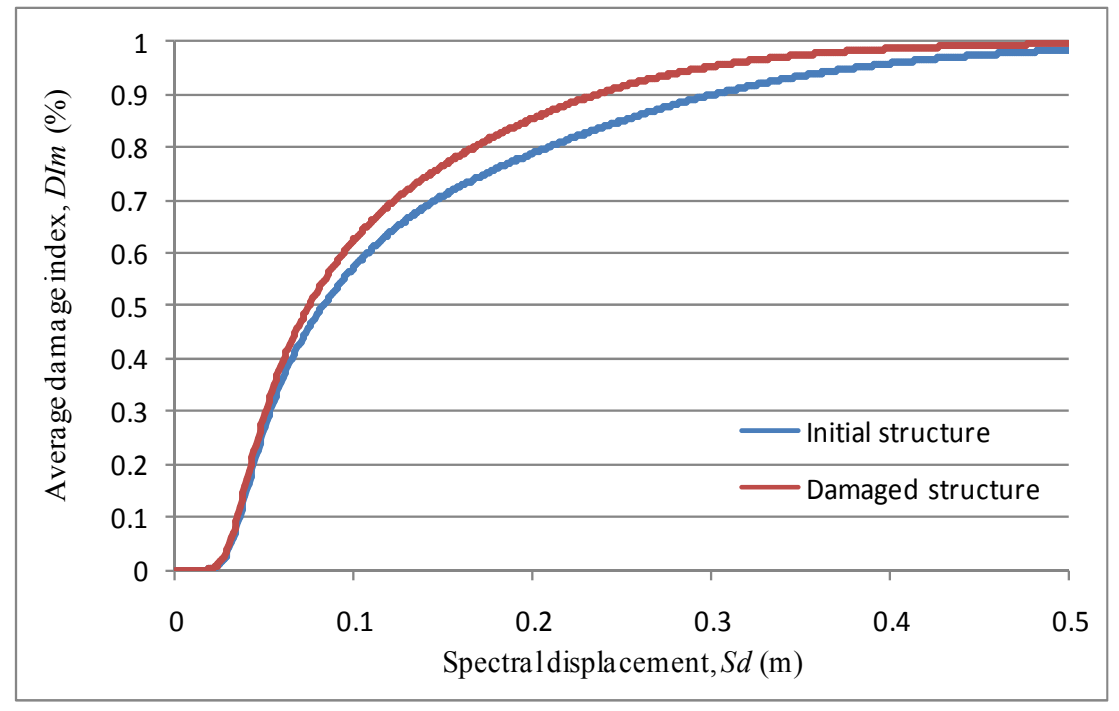

Fig. 9 - Vulnerability curves for oy direction

\section{Conclusions}

The paper shows a fast and easy to handle method to evaluate the vulnerability of structure, which can be applied to existing old structures, or to new structures which occurred problems during execution. Following this method one can calculate the probability of damage stages in several situations of the structure. In our example, we show a comparison of the damage index for the 2 stages of the structure. The authors will continue this study by taking into account the strengthening solution with concrete walls, and applying the method also to this 3rd situation. As the position of the strengthening elements will never be according to the demands of the structural rules, it results the necessity of more complex analysis of some areas. They can be carried out using a very detailed model of the structure and taking into consideration the propagation of the concrete cracks. 


\section{References}

[1]. Barbat A.H., Pujades L.G., Lantada N. (2008), Seismic Damage Evaluation in Urban Areas Using the Capacity Spectrum Method: Application to Barcelona. Soil Dyn. a. Earthquake Engng., 28, 10, 851-865.

[2]. Benedetti D., Petrini V. (1984), Sulla vulnerabilita sismica di edifici in muratura i proposte di un metodo di valutazione. L'industria delle Construzioni, 149, 66-74.

[3]. Calvi G.M., Magenes G., Bommer J.J., Pinho R., Crowley H., Restrepo-Vélez L.F. (2006), Displacement-Based Methods for Seismic Vulnerability Assessment at Variable Geographical Scales. ISET J. Earthquake Technol, 43, 3, 75-104.

[4]. Fajfar P. (2000), A Nonlinear Analysis Method for Performance Based Seismic Design. Earthquake Engng. A. Struct. Dyn., 16, 3, 573-592.

[5]. Freeman S.A.( 1978), Prediction of Response of Concrete Buildings to Severe Earthquake Motion. Proc. of Douglas McHenry Internat. Symp. on Concrete a. Concrete Struct., publication SP-55, Amer. Concrete Inst., Detroit, Michigan, USA.

[6]. Grünthal G.(1998), European Macroseismic Scale. Vol. 15, Luxemburg: Centre Européen de Géodynamique et Séismologie, Cahiers du Centre Européen de Géodynamique et de Séismologie

[7]. Milutinovic Z.V., Trendafiloski G.S.,(2003), RISK-UE, an Advanced Approach to Earthquake Risk Scenarios with Applications to Different European Towns. Contract: EVK4-CT-2000-00014, WP4: Vulnerability of Current Buildings.

[8]. Nour El-Din Abd-Alla M. (2007), Application of Recent Techniques of Pushover for Evaluating Seismic Performance of Multistory Buildings. M. Sc. Diss., Faculty of Engng, Cairo Univ., Egypt.

[9]. Riddell R., Llera J.C. (1996), Seismic Analysis and Design: Current Practice and Future Trends. Proc. of 11th World Conf. on Earthquake Engng., Acapulco, Mexico, Paper No. 2010, 1-12.

[10]. Sobol I.M. (1983), Método de Montecarlo. Ed. Mir, Moscow.

[11]. Zou X.K., Chan C.M. (2005), Optimal Seismic Performance-Based Design of Reinforced Concrete Buildings Using Non-Linear Pushover Analysis. Engng. Struct., 27, 1289-1302.

[12]. Pastia, C. , S.G. Luca (2013), Vibration Control of A Frame Structure using Semi-Active Tuned Mass Damper, Bul. I.P., Iaşi, Tomul LIX (LXIII), Fasc. 4, pp. 31-40.2.

[13]. P100 / 2006 and 2013 Romanian code for seismic Design.

[14]. http://s276.photobucket.com/user/MaryLou4/media/image012.jpg.html

[15]. Olteanu, I., Barbat, A.H., Budescu, M. (2015), Vulnerability Assessment of Reinforced Concrete Framed Structures Considering the Effect of Structural Characteristics, The Open Civil Engineering Journal, 2015, 9, pp 321-329 